\title{
ANALISIS PEMASARAN JAGUNG DI KABUPATEN LABUHANBATU SELATAN
}

\author{
Rahmanta \\ Program Studi Agribisnis dan Pascasarjana Fakultas Pertanian \\ Universitas Sumatera Utara \\ Email: rahmanta@usu.ac.id
}

\begin{abstract}
Marketing on corn trends to concentration and distribute where both of commodities produced in many places in raw materials needs, continiuty of the commodities processing in the low volume to cover costs in marketing in function. Corn marketing the concertration shorts from gathering the agriculture of product from farmers to gatherers, stock gatheres and by trades and ends in distribution case. It works from agents, retailer to consument. The study aims to identify how the marketing line of corn and share margin of market on every line of marketing: primer and secondary data got from farmer and corn trader. Analyze Methods are marketing line, marketing major, price spread and share margin. The study research resulted that these are two forms of corn marketing, they are: (a) Farmer - trader - gatherer - farm store or retailer - consument, (b) Farmer - farm shop or retailer-consunment. Most of the farmers market the on the first line it's about $70 \%$ and the rest one is about $30 \%$ on the second one. Margin profit received by the traders is bigger than received by the farmers, either on the first marketing line or the second one
\end{abstract}

Key words : corn price, marketing line, marketing margin, share margin.

\section{PENDAHULUAN}

ecara umum pemasaran dianggap sebagai proses aliran barang yang terjadi dalam pasar. Dalam pemasaran ini barang mengalir dari produsen sampai kepada konsumen akhir yang disertai penambahan guna bentuk melalui proses pengolahan, guna tempat melalui proses pengangkutan dan guna waktu melalui proses penyimpanan. Sebagai proses produksi yang komersial maka pemasaran pertanian merupakan syarat mutlak yang diperlukan dalam pembangunan pertanian yang memberikan nilai tambah yang dapat dianggap sebagai kegiatan produktif. Pemasaran pertanian adalah proses aliran komoditi yang disertai perpindahan hak milik dan penciptaan guna waktu, guna tempat, dan guna bentuk yang dilakukan oleh lembaga- 
lembaga pemasaran dengan melaksanakan satu atau lebih fungsi-fungsi pemasaran.

Pemasaran komoditi pertanian bersifat konsentrasi dan distributif dimana komoditi tersebut dihasilkan secara terpencar-pencar berupa bahan mentah yang perlu pengolahan lebih lanjut dan dalam jumlah yang relatif sedikit sehingga untuk menutup biaya-biaya yang diperlukan lembaga pemasaran dalam melakukan fungsi-fungsi pemasaran dan memerlukan volume perdagangan yang cukup besar. Pemasaran komoditi pertanian dari proses konsentrasi yaitu pengumpulan produk-produk pertanian dari petani ke tengkulak, pedagang pengumpul dan pedagang besar serta diakhiri proses distribusi yaitu penjualan barang dari pedagang agen, pengecer, dan konsumen.

Sistem pemasaran biasanya berkisar pada kegiatan antara pemasok barang dan jasa, perusahaan, dan pasar. Hubungan ketiga komponen ini biasanya dipengaruhi oleh faktor lingkungan dan kegiatan lain. Hubungan antara pemasok dan perusahaan sangat bergantung pada kesepakatan bisnis antara keduanya. Agar keduanya saling diuntungkan maka biasanya kedua belah pihak membuat kesepakatan jual beli.

Komoditi pertanian memiliki ciri yang khas antara lain produk pertanian adalah musiman, bersifat segar dan mudah rusak, bersifat "bulky" artinya volumenya besar tetapi nilainya relatif kecil, lebih mudah terserang hama dan penyakit, tidak selalu mudah didistribusikan ke lain tempat, bersifat lokal atau kondisional, mempunyai kegunaan yang beragam, dan sebagainya. Sehingga terdapat beberapa masalah pemasaran komoditi pertanian yang dihadapi di daerah antara lain : (a) tidak tersedianya komoditi pertanian dalam jumlah yang cukup dan kontinu, (b) fluktuasi harga, (c) pelaksanaan pemasaran yang tidak efisien, (d) tidak memadainya fasilitas pemasaran, (e) terpencarnya lokasi produsen dan konsumen, (f) kurang lengkapnya informasi pasar, (g) kurangnya pengetahuan terhadap pemasaran, (h) kurang responnya produsen terhadap permintaan pasar

Komoditi pertanian yang diperjualbelikan beraneka ragam, lembagalembaga pemasaran yang terlibat dalam proses pemasaran banyak, satu lembaga pemasaran dapat melakukan satu atau lebih fungsi pemasaran serta adanya kekuatan pembeli dan penjual dalam menentukan harga. Tugas lembaga pemasaran adalah menjalankan fungsi-fungsi pemasaran 
serta memenuhi keinginan konsumen semaksimal mungkin. Konsumen memberikan balas jasa kepada lembaga pemasaran ini berupa margin pemasaran.

\section{METODE PENELITIAN}

Metode Penentuan Daerah Penelitian

Daerah penelitian dilaksanakan di Kabupaten Labuhanbatu Selatan. Daerah penelitian ini dipilih secara sengaja (purposive) dengan mempertimbangkan bahwa Kabupaten Labuhanbatu Selatan salah satu daerah yang memiliki potensi dalam pengembangan budidaya tanaman jagung.

Populasi dan Sampel

Populasi dalam penelitian ini yaitu petani dan pedagang jagung, proses pengambilan sampel dari populasinya dinamakan sampling dan bila seluruh populasi diambil dinamakan sensus. Populasi adalah kumpulan dari individu dengan kualitas serta ciri-ciri yang telah ditetapkan.

Sampel adalah bagian dari populasi. Survei sampel adalah suatu prosedur dalam mana hanya sebagian dari populasi saja yang diambil dan dipergunakan untuk menentukan sifat serta ciri yang dikehendaki dari populasi.

Besarnya sampel dalam perumusan pemasaran jagung adalah sebanyak 30 orang, hal ini sesuai dengan pendapat Roscoe dalam Sugiyono (2006) ukuran sampel yang layak dalam suatu penelitian minimal sebesar 30 orang. Jumlah anggota sampel ini terdiri dari : (1) petani jagung sebesar 20 orang, (2) pedagang pengumpul atau agen kecil sebesar 5 orang, (3) pedagang besar atau agen besar sebesar 5 orang, (4) pedagang pengecer sebesar 5 orang, sehingga jumlah sampel seluruhnya sebesar 35 orang.

Model Analisis

Secara garis besar, metode pelaksanaan kegiatan meliputi 2 (dua) pendekatan yaitu kuantitatif dan kualitatif. Dalam pendekatan kuantitatif akan dilakukan pengumpulan berbagai data-data pendukung terkait dengan existing conditions pemasaran jagung di Kabupaten Labuhanbatu Selatan. 
Model analisis yang digunakan yaitu margin pemasaran, price spread dan share margin dengan menggunakan rumus :

Untuk margin pemasaran :

$$
\begin{aligned}
& \text { Mji }=\text { Psi }- \text { Pbi } \\
& \text { Mji }=b t i+\mu i \\
& \mu i=m j i-b t i
\end{aligned}
$$

Sehingga margin pemasaran total adalah

$$
\mathrm{Mj}=\sum \mathrm{mji}
$$

\section{Dimana :}

Mji = Margin pada lembaga pemasaran ke-i

Psi = Harga penjualan pada lembaga pemasaran ke-i

$\mathrm{Pbi}=$ Harga pembelian lembaga pemasaran ke-i

bti = Biaya pemasaran lembaga pemasaran ke-i

$\mu \mathrm{i}=$ Keuntungan lembaga pemasaran

$\mathrm{Mj}=$ Margin pemasaran total

i $=1,2,3, \ldots, n$

Untuk menghitung share margin :

$$
\begin{aligned}
& \mathrm{Pp} \\
& \mathrm{Sm}=(\mathrm{pp} / \mathrm{pk}) \times 100 \%
\end{aligned}
$$

$\mathrm{Pk}$

Dimana

$\mathrm{Sm}=$ Share margin

$\mathrm{Pp}=$ Harga yang diterima dari produsen

$\mathrm{Pk}=$ Harga yang dibayar oleh konsumen akhir

Untuk Price spread diperoleh dengan mengelompokkan biaya-biaya tata niaga yang dikeluarkan oleh setiap lembaga pemasaran dari setiap saluran pemasaran yang ada. 


\section{HASIL DAN PEMBAHASAN}

Saluran Pemasaran Jagung

Sistem pemasaran jagung di daerah penelitian terdiri atas 3 sub sistem, yang saling berkaitan, yaitu :

(a) Produsen/Petani Jagung, (b) Pedagang perantara meliputi padagang pengumpul dan pedagang pengecer/toko tani, (c) Konsumen, yaitu mereka yang membeli jagung dari pedagang perantara untuk di konsumsi

Keseluruhan sistem ini memiliki tujuan yang sama yakni mendistribusikan jagung dari lahan pertanian sampai ke tangan konsumen, sehingga dalam pergerakan sub sistem ini terbentuklah saluran pemasaran. Untuk medistribusikan jagung sampai ketangan konsumen setiap lembaga pemasaran melakukan fungsi pemasaran dan menimbulkan biaya pemasaran.

Produsen (petani jagung) melakukan kegiatan pembelian input-input produksi, penanaman, pemeliharaan jagung hingga ke pemanen. Harga jagung yang di jual petani ke pedagang perantara befluktuasi tergantung pada tinggi rendahnya kadar air jagung. Makin rendah kadar air jagung maka harga jual akan semakin tinggi pula.

Di Kecamatan Torgamba hasil panen jagung terlebih dahulu dipipil oleh petani sendiri, kemudian di jual ke pada pedagang pengumpul atau langsung ke toko tani, dari toko tani di jual langsung kepada konsumen.

Berdasarkan hasil pengamatan dilapangan terdapat 2 jenis saluran pemasaran jagung di daerah penelitian. Untuk lebih rinci dapat dilihat pada gambar di bawah ini.

\section{a) Saluran Pemasaran Jagung I}

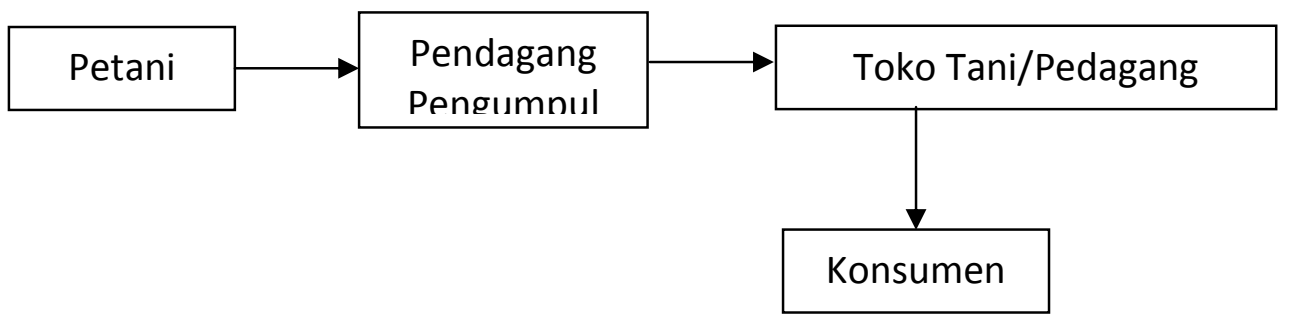

Gambar 1. Saluran Pemasaran Jagung I 
Pada saluran pemasaran pertama, petani terlebih dahulu memipil jagung hasil panennya. Kemudian petani menjual jagung pipilan kering ini ke pedagang pengumpul. Dari pedagang pengumpul jagung pipil ini di jual langsung ke Toko Tani (Toko Bintang Tani) yang berada di Kabupaten Labuhanbatu Selatan atau Kota Pinang. Toko Tani (Bintang Tani) sebagai pedagang pengecer. Pedagang pengecer menjual langsung kepada konsumen untuk pakan ternak. Untuk mengetahui biaya dari masingmasing lembaga pemasaran, dapat dilihat berdasarkan saluran pemasaran jagung yang ada.

Umumnya petani tidak menjual Jagung pipilan langsung ke toko tani karena alat transportasi yang terbatas, pedagang pengumpul yang biasanya membeli jagung dari petani dengan alasan agar meminimalisir atau mengurangi biaya.

Saluran Pemasaran Jagung II

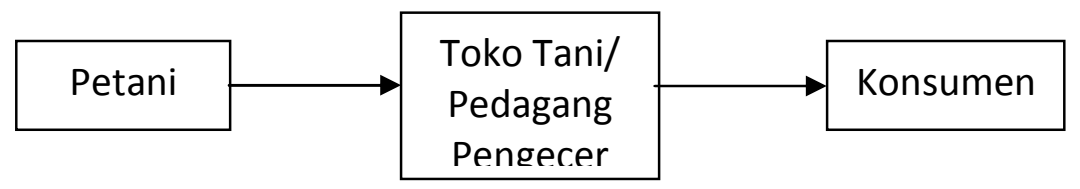

Gambar 2. Saluran Pemasaran Jagung II

Dari gambar di atas diketahui pada saluran pemasaran jagung ke II petani langsung membawa jagung pipilan langsung ke toko tani (Bintang tani) berbeda dengan saluran I yang menjual jagung pipilannya ke pada pedangang pengumpul terlebih dahulu. pada saluran ini petani langsung menjual pada toko, karena petani memiliki keuntungan lebih besar bila menjual langsung ke toko tani dari pada melalui pedagng pengumpul.

Berdasarkan hasil penelitian sebagaian besar petani memasarkan jagungnya pada bentuk saluran pemasaran II, yaitu sekitar 70 persen, dan sisanya sebesar 30 persen lagi petani memasarkan jagung pada bentuk saluran pemasaran I. Bentuk salauran II ini lebih pendek dari pada saluran pemasaran I sehingga dapat menghemat biaya saluran pemasaran jagung dan pada akhirnya dapat meningkatkan harga jual petani dan pendapatan yang diterima oleh petani jagung. 
Biaya Pemasaran, Price Spread dan Share Margin pada Setiap Saluran Pemasaran Jagung

Untuk menganalisis price sread dan margin pemasaran di setiap saluran pemasaran jagung maka perlu dihitung biaya pemasaran yang dikeluarkan oleh masing-masing lembaga pemasaran. Untuk mengetahui biaya dari masing-masing petani dan lembaga pemasaran dapat dilihat berdasarkan saluran pemasaran jagung yang ada.

a) Petani - Pedagang Pengumpul - Toko Tani/Pedagang Pengecer Konsumen

Dari setiap periode panen pedagang pengumpul membeli jagung dari petani sekitar $200 \mathrm{~kg}$ - $300 \mathrm{~kg}$ dalam bentuk jagung pipilan. Dengan ratarata pembelian $250 \mathrm{~kg}$, harga beli pedagang pengumpul ke petani bervariasi tergantung oleh kadar air jagung. Rata-rata harga beli jagung dari pedagang pengumpul ke petani adalah Rp. 4100/kg.

Pedagang pengumpul menjual jagung pipilan tersebut ke toko tani. Harga jual pedagang pengumpul ke toko tani bervariasi tergantung kadar air jagung tersebut dengan harga jual rata-rata Rp. $4500 / \mathrm{kg}$.

Biaya pemasaran yang di tanggung oleh pedagang pengumpul terdiri dari biaya transportasi dan upah bongkar muat sebesar Rp. 150/kg, biaya yang dikeluarkan hanya trasportasi dan upah bongkar muat di karenakan dekatnya jarak dari desa ke toko tani. Keuntungan yang di peroleh pedagang pengumpul dalam penjualan jagung pipilan adalah Rp. $250 / \mathrm{kg}$.

Dari pedaganng pengumpul, jagung tersebut di jual kepada toko tani (pedagang pengecer), dan toko tani (pedagang pengecer) menjual jagung pipilan tersebut ke konsumen dengan harga rata-rata Rp. 6000/kg dan keuntungan yang di peroleh toko tani (pedagang pengecer) rata-rata sebesar Rp. $1400 / \mathrm{kg}$.

Dari uraian diatas dapat dibuat biaya pemsaran, price spread, share margin dan profit margin per $\mathrm{kg}$ jagung pada saluran pemasaran tersebut sebagar berikut: 
Tabel 1. Komponen biaya, Price Spread, dan Share Margin Jagung Pipil Kering per Kg Saluran I

\begin{tabular}{|c|c|c|c|c|c|}
\hline No & Uraian & & $\begin{array}{l}\text { Nilai/Price } \\
\text { (Rp/Kg) }\end{array}$ & Spread & $\begin{array}{l}\text { Share } \\
(\%)\end{array}$ \\
\hline \multirow[t]{4}{*}{1} & Tingkat & Petani & & & \\
\hline & a) & Biaya Produksi & 3500 & & 58,33 \\
\hline & b) & Profit Margin & 600 & & 0,10 \\
\hline & c) & Harga Jual & 4100 & & 68,33 \\
\hline \multirow[t]{7}{*}{2} & Tingkat & Pedagang Pengumpul & & & \\
\hline & a) & Harga Beli Jagung & 4100 & & 68,33 \\
\hline & b) & Biaya Pemasaran & & & \\
\hline & - & Transportasi & 50 & & 0,83 \\
\hline & - & Tenaga Kerja & 100 & & 1,67 \\
\hline & c) & Profit Margin & 250 & & 4,17 \\
\hline & d) & Harga Jual & 4500 & & 75,00 \\
\hline \multirow[t]{7}{*}{3} & Tingkat & Toko Tani & & & \\
\hline & a) & Harga Beli & 4500 & & 75,00 \\
\hline & b) & Biaya Pemasaran & & & \\
\hline & - & Sewa Tempat & 50 & & 0,83 \\
\hline & - & Packing & 50 & & 0,83 \\
\hline & c) & Profit Margin & 1400 & & 23,33 \\
\hline & d) & Harga Jual & 6000 & & 100,00 \\
\hline 4 & Harga B & eli Konsumen & 6000 & & 100,00 \\
\hline
\end{tabular}

Sumber : Analisis Data Primer 2016

b) Petani - Toko Tani/Pedagang Pengecer

Selanjutnya rincian mengenai biaya pemasaran, price spread dan share margin untuk saluran pemasaran jagung ke II dapat dilihat pada tabel di bawah ini.

Tabel 2. Komponen Biaya, Price Spread, dan Share Margin Jagung Pipil Kering per Kg Saluran II

\begin{tabular}{|c|c|c|c|c|c|}
\hline No & Uraian & $\begin{array}{l}\text { Nilai/Price } \\
\text { (Rp/Kg) }\end{array}$ & Spread & $\begin{array}{l}\text { Share } \\
(\%)\end{array}$ & Margin \\
\hline \multirow[t]{4}{*}{1} & Tingkat Petani & & & & \\
\hline & a) Biaya Produksi & 3500 & & 58,33 & \\
\hline & b) Biaya Transportasi & 100 & & 1,67 & \\
\hline & c) Biaya Tenaga Kerja & 100 & & 1,67 & \\
\hline
\end{tabular}

QE Journal | Vol.05 - No. 04 Desember 2016 - 216 


\begin{tabular}{|c|c|c|c|c|}
\hline & d) & Profit Margin & 800 & 13,33 \\
\hline & e) & Harga Jual & 4500 & 75,00 \\
\hline \multirow[t]{7}{*}{2} & Tingkat & 「oko Tani & & \\
\hline & a) & Harga Beli & 4500 & 75,00 \\
\hline & b) & Biaya Pemasaran & & \\
\hline & - & Sewa Tempat & 50 & 0,83 \\
\hline & - & Packing & 50 & 0,83 \\
\hline & c) & Profit Margin & 1400 & 23,33 \\
\hline & d) & Harga Jual & 6000 & 100,00 \\
\hline 3 & Harga B & eli Konsumen & 6000 & 100,00 \\
\hline
\end{tabular}

Sumber : Analisis Data Primer 2016

Rata-rata harga jual jagung dari petani ke toko tani adalah Rp. 4500/kg dimana biaya pemasaran yang di tanggung oleh petani terdiri dari biaya transportasi dan biaya tenaga kerja atau upah bongkar muat sebesar Rp. 200/kg, dan keuntungan yang diperoleh petani dalam penjualan jagung pipilan adalah Rp. 800/kg. Dari toko tani (pedagang pengecer) menjual jagung pipilan tersebut ke konsumen dengan harga rata-rata Rp. 6000/kg, dan keuntungan yang di peroleh toko tani (pedagang pengecer) rata-rata sebesar Rp. 1400/kg.

\section{KESIMPULAN DAN SARAN}

Kesimpulan

Berdasarkan hasil penelitian dan pembahasan yang telah diuraikan, maka dapat disimpulkan sebagai berikut :

a) Terdapat 2 (dua) bentuk saluran pemasaran jagung, yaitu: (a) Saluran I : Petani - Pedagang Pengumpul - Toko Tani atau Pedagang Pengecer Konsumen, (b) Saluran II : Petani - Toko Tani atau Pedagang Pengecer - Konsumen.

b) Sebagaian besar petani memasarkan jagungnya pada bentuk saluran pemasaran II, yaitu sekitar 70 persen, dan sisanya sebesar 30 persen lagi petani memasarkan jagung pada bentuk saluran pemasaran I.

c) Saluran pemasaran I dan II dimana profit margin yang diterima oleh pedagang lebih besar daripada yang diterima petani. 
d) Sektor pertanian, khususnya tanaman jagung di daerah penelitian saat ini masih merupakan sebagai sumber penghasilan atau penyedia lapangan pekerjaan sebagian besar penduduk.

Saran

Berdasarkan pembahasan dan kesimpulan maka dapat disarankan adalah sebagai berikut :

a) Kepada pemerintah agar lebih memperhatikan sektor pertanian khususnya tanaman pangan karena sebagian besar penduduknya masih menggantungkan hidupnya pada sektor tersebut, dengan cara kebijakan membangun sarana dan prasarana yang berkaitan dengan sektor pertanian.

b) Perlu adanya pengolahan bahan baku dari hasil pertanian lebih lanjut, seperti pengolahan biji jagung menjadi jagung pipilan, dengan kebijakan bantuan mesin pengolahan hasil pertanian ke petani dalam rangka meingkatkan nilai tambah dari paroduk olahan tersebut.

c) Meningkatkan efisiensi saluran pemasaran pertanian dengan cara kebijakan mengurangi stakeholders yang terlibat dalam pemasaran hasil pertanian dalam rangka meningkatkan harga jual dan pendapatan petani.

\section{DAFTAR PUSTAKA}

Assauri, Sofjan. 2007. Manajemen Pemasaran. PT. Raja Grafindo Persada. Jakarta.

Basu Swasta dan T. Hani Handoko, William J. Stanton. 2004. Management Pemasaran Modern. PT. Grasindo Persada. Jakarta.

Badan Pusat Statistik, 2016. Labuhanbatu Selatan Dalam Angka 2016. Kabupaten Labuhanbatu Selatan, Kota Pinang.

Direktorat Jenderal Bina Pengolahan dan Pemasaran Hasil Pertanian Departemen Pertanian. 2001. Kebijakan dan Program Pembangunan Pemasaran Hasil Pertanian 2001-2004. Departemen Pertanian RI, Jakarta.

Kotler, P. 2005. Manajamen Pemasaran, Jilid 1 dan 2. PT. Indeks Kelompok Gramedia. Jakarta. 
Krisnamurthi, B. 2014. Kebijakan untuk Petani : Pemberdayaan untuk Pertumbuhan dan Pertumbuhan yang Memberdayakan. Disampaikan pada Pembukaan Konferensi Nasional XVII dan Kongres Nasional XVI Perhepi, Bogor.

Rangkuti, F. 1997. Riset Pemasaran. PT. Gramedia Pustaka Utama. Jakarta Rahmat Rukmana. 1997. Usaha Tani Jagung. Penerbit Kanisius. Jogjakarta Sugiyono. 2006. Metode Penelitian Administrasi. Alfabeta, Bandung. Soekartawi. 2006. Analisis Usahatani. UI Press. Jakarta. 